\title{
The Cultural Mission of China’s Elite Universities: Examples from Peking and Tsinghua
}

\author{
Rui Yang \\ University of Hong Kong \\ yangrui@hku.hk
}

\begin{abstract}
Since the late $19^{\text {th }}$ century, China, as a latecomer to modernization, has prioritized Western learning. The first modern university was created in China in 1895 to serve such a purpose with little linkage to China's rich indigenous cultural traditions. Modelled on European and North American experiences and operating in a Confucian socio-cultural context, Chinese universities have long been struggling with their cultural identity. In line with recent development, China's higher education has made impressive progress, and cultural experiment has been placed increasingly highly on the agenda. With an understanding of Chinese and Western knowledges by the elites, China's very best universities have the promise to integrate both traditions in their day-to-day operation. Such a bi-culturality, or even multi-culturality, is in stark contrast to the still largely mono-cultural university operation environment in the West. The integration would open spaces for Chinese universities to explore an alternative to Western models that have dominated world's higher education since Western industrialization. Based on fieldwork at Peking and Tsinghua Universities in Beijing, this article reports some findings from a three-year project supported by the Hong Kong Research Grants Council. It attempts to suggest a different angle to observe China's experience in higher education. It argues that cultural experiment would enable top Chinese universities to bring back their cultural traditions to integrate with Western values, and thus contribute to inter-civilizational dialogue.
\end{abstract}

Key words higher education, China, inter-civilizational dialogue, cultural mission, Peking University, Tsinghua University

\section{Introduction}

Over the last few decades, higher education development in China has been remarkable. China's higher education system is fast improving in both quality and quantity. Her well-established modern system has become the world's largest in terms of sheer numbers of students and teachers. By 2016, 36.99 million students enrolled in China's 2,596 regular and 284 adult higher education institutions, with a gross enrolment rate of $42.7 \%$. Annual postgraduate admissions reached 667,100, with 589,800 and 77,300 respectively at Master's and doctoral levels and a total of 1,981,100 at-school postgraduate students. There were 742 private higher education institutions, enrolling 715 Master's, 3,915,200 undergraduate and 2,424,600 associate degree students (Ministry of Education 2017). China began to build world-class universities in the 1990s, with Projects 211 and Project 985 initiated in 1993 and 1998 respecxtively and the "Double First-class University” in 2016. Together with substiantial financial and human resource commitments, China's efforst have begun to pay off. Today Chinese universities are rigorous in setting global quality research as their performance standard. They are making an increasing impact on a global scale. In the latest published Academic Rankings of World Universities by Shanghai Jiao Tong University (ARWU 2017), for example, China and the US are the two biggest hopefuls. Mainland Chinese universities made forty-five spots out of the top 500, with Tsinghua and Peking standing respectively at the $48^{\text {th }}$ and $71^{\text {st }}$ places. 
As for research, China's capacity has grown rapidly, and now quality is on the rise (Van Noorden 2016). China is the world's $3^{\text {rd }}$ largest producer of peer-reviewed research articles, after the European Union and the United States (Marginson 2014, Rhoads, et al. 2014). Out of the world's 827,705 articles published in 2011, researchers in the combined 28 European Union countries produced 254,482 articles (31\%), the United States 212,394 (26\%), China 89,894 (11\%) and Japan 47,106 (6\%) (Kigotho 2014). The number of papers authored by Chinese scientists grew an average of more than 15\% annually during 2001-2011, rising from 3\% of global research article output to $11 \%$ over the decade (Morrison 2014). According to China Institute of Science and Technology Information, Chinese researchers published 16,900 world top 1\% highcited papers accounting for $12.8 \%$ of the global share during 2006-2016. By October 2016, China was the $3^{\text {rd }}$ largest producer of high-cited international papers; the $2^{\text {nd }}$ most cited papers in agricultural science, chemistry, computer science, engineering, materials science, mathematics, pharmacy and toxicology, and physics; and the $2^{\text {nd }}$ for six years consecutively in terms of numbers of papers published in world's most influential international journals. Furthermore, Chinese researchers are collaborating more internationally in research and publication. Both the number of Chinese scientific journals entering disciplinary forefronts and their global influence are increasing (Guo 2016). China is fast evolving from an imitator to an innovator and the style of innovation in China lends itself to knowledge-based research and development.

While there is consensus on China's recent achievement in higher education, an assessment regarding her future development is less certain. To some, Chinese universities are leaping ahead to challenge Western supremacy (Morgan 2011). To others, China's universities generally still lag behind the best in the West. Their notion of 'world-class' status has been largely imitative rather than creative (Mohrman 2005). A kind of "glass ceiling” is to be reached soon with feet of clay (Altbach 2016). Studies of Chinese higher education reforms have been overwhelmed by the powerful influence of economic and political realities. The literature focuses on the ecomnomic and social functions of higher education in China's development (Min 1991; Jacob 2006; Li, et al. 2011). Except the systematic studies by Hayhoe (1996) and some recent works by Yang (2011) and Hawkins (2013), a cultural perspective that gives weight to the impact of traditional ways of thinking on contemporary development has been much lacking in the English literature. There is also a mismatch between Western theoretivcal frameworks and China's higher education realities (Wang 2010).

Chinese modern universities are foreign transplants (Hayhoe 1996). Forging their identity is inevitably an arduous task. China's strikingly different cultural roots and heritages have led to continuous conflicts between indigenous and Western higher education values. The establishment of modern universities in China has been based on Western values on the one hand, and a system supported by traditional culture on the other. The two systems often do not support each other. Instead, constant tensions between them reduce the efficiency of university operation. Although there have been strong attempts to indigenise the Western idea of a university (Yang 2013), little has been achieved. The Western concept of a university had been adopted for its practicality. This is why China's achievements in science and technology are so much greater than those in the social sciences and humanities. Some even ask whether or not this bottleneck would become a "middle-income trap" in China's higher education development (Yang 2016). It is also the basis for the notion of glass ceiling and feet of clay (Altbach 2016). With both extraordinary achievements and enormous difficulties, people wonder how to come to terms with China's current and future higher education development and its implications for the region and beyond. 
While there is evident pride in the idea that Chinese universities are not willing to assume that Western models define excellence, few - both within and outside China - have been able to theorise their differences from Western universities. While universities are by nature cultural institutions, their historical role and cultural mission have been much ignored, leading to incomplete, inappropriate and even misleading assessments of their contemporary and future development. Reporting findings from a recent study supported by the Hong Kong Research Grants Council, this article proposes that integrating the seemingly contradictory Chinese and Western ideas of a university is increasingly likely. Using China's Peking and Tsinghua Universities as examples, it points out emerging signs of hope and argues that the combination is globally significant and historically unprecedented. While cautioning that China's top universities will not necessarily achieve their goals without twists and turns, and perhaps they will not necessarily succeed, this article argues that the conventional binary positioning of Chinese and Western traditional ideas of a university in the literature needs to be rethought.

\section{Methods}

What is reported in this article is part of a project of a comparative policy analysis, focusing on the quest for world-class university status in the higher education sectors of the Chinese mainland, Hong Kong, Taiwan and Singapore, located within a 'bigger picture' of globalization. Policy here is defined broadly to include "both text and action, words and deeds, it is what is enacted as well as what is intended” (Ball 1994, 10). A broad policy analysis approach was used to allow policy to be found not only at the macro level of central government but also at the micro level in individual institutions to include the perspectives of practitioners (Henry et al. 1997). This study tracked policy on building world-class universities from global contexts through societal level policies to policy reconstruction and practices in individual higher education institutions.

Case study research was adopted to fully understand the themes of the project, due to its recognition of both the complexity and the context (Hargreaves 1993). Peking and Tsinghua Universities were chosen because they embrace international norms in the top layer in China to create world-class universities on the Chinese soil (Marginson 2006). They represent both of the two major types of institutions (comprehensive and technological) in the Chinese sector and a continuum of policy change in the domains of world-class universities as they reposition themselves in a global arena where education is the centrepiece. Cross-case analyses were undertaken to identify common themes and major differences within and between them to build an understanding of rapidly evolving policies on higher education in a context of globalisation.

The sampling was 'purposive' (Punch 2009). In each university, participants were drawn from both administrators and grassroots academics. Initial approach was made through personal and professional contacts. Then, by 'snowball' sampling (Punch 2009), participants were asked to identify others for the study. They included eight from Peking University and eleven from Tsinghua University. Many held academic and administrative leadership positions at that time, as shown in Tables 1 and 2 below. All participants were required to have at least five years' experience in their institutions in order to obtain a sense of changes in each case over the time period under study.

The research used two instruments to gather the reported data: document analysis and indepth semi-structured interviews. Documents are an important source of rich and valuable data in education and social science research (Travers 2001). They are especially important in a policy analysis study. For each university, a series of high level policy documents relevant to the push 
towards world-class status, from institutional mission/vision statements, strategic plans to leaders' speeches, were collected, reviewed and interrogated to analyse the context for policy on building world-class universities (O’Leary 2004). They were also used to examine the localised context and specific policies on becoming world-class in each case study university prior to the collection of interview data.

In-depth semi-structured interviews were used to access the 'lived experience' of participants in relation to the policy on building world-class universities (Marshall and Rossman 2006). They were scheduled flexibly to encourage participants to talk as much as they pleased on different issues as they arose, with 'core' questions asked at each case to make comparisons and contrasts for triangulation purposes between different localised sites. They were conducted in Mandarin and lasted normally for an hour, with the shortest for thirty-two minutes and the longest one hour and forty minutes. All interviews were taped and later transcribed.

There were two stages of analysing the data set. Stage one identified important themes in answering the research questions, following Miles and Huberman's (1994) approach. Stage two used the themes for cross-case comparisons. Documents at both societal and institutional levels were collected and analysed to identify key features of the policy on world-class university for the society and universities. Collection of the empirical data reported in this article occurred in Beijing in May 2014. Analysis of interview data was then conducted, followed by triangulation of document data with interview data within and between the cases.

\section{Table 1: Interviewees from Peking University}

\begin{tabular}{|lclllll|}
\hline Interviewee & Gender & Age & PhD & Discipline & Professional Rank & Administrative Level \\
\hline BJ-1 & M & $50-60$ & Overseas & Science & Professor & Department Head \\
\hline BJ-2 & M & $40-50$ & Domestic & Social Science & Professor & $\begin{array}{l}\text { Mid-level University } \\
\text { Administration }\end{array}$ \\
\hline BJ-3 & M & $40-50$ & Domestic & Social Science & Professor & Faculty Dean \\
\hline BJ-4 & F & $50-60$ & Overseas & Science & Professor & - \\
\hline BJ-5 & M & $40-50$ & Overseas & Science & Professor & $\begin{array}{l}\text { Mid-level University } \\
\text { Administration }\end{array}$ \\
\hline BJ-6 & M & $40-50$ & Domestic & Social Science & Associate Professor & $\begin{array}{l}\text { Mid-level University } \\
\text { Administration }\end{array}$ \\
\hline BJ-7 & M & $40-50$ & Domestic & Social Science & Associate Professor & $\begin{array}{l}\text { Mid-level University } \\
\text { Administration }\end{array}$ \\
\hline BJ-8 & F & $50-60$ & Overseas & Social Science & Professor & Centre Director \\
\hline
\end{tabular}


Table 2: Interviewees from Tsinghua University

\begin{tabular}{|lllllll|}
\hline Interviewee & Gender & Age & PhD & Discipline & Professional Rank & $\begin{array}{l}\text { Administrative } \\
\text { Level }\end{array}$ \\
\hline QH-1 & M & $60-70$ & Domestic & Engineering & Professor & $\begin{array}{l}\text { University-level } \\
\text { Administration }\end{array}$ \\
\hline QH-2 & M & $50-60$ & Overseas & Science & Professor & - \\
\hline QH-3 & M & $50-60$ & Domestic & Social Science & Professor & Faculty Dean \\
\hline QH-4 & F & $50-60$ & Overseas & Human Science & Professor & Department Head \\
\hline QH-5 & F & $40-50$ & Domestic & Social Science & Associate Professor & Office Director \\
\hline QH-6 & M & $60-70$ & Overseas & Engineering & Professor & Former University \\
& & & & & Leader \\
\hline QH-7 & M & $50-60$ & Overseas & Engineering & Professor & Centre Director \\
\hline QH-8 & M & $60-70$ & Domestic & Social Science & Professor & Faculty Dean \\
\hline QH-9 & F & $50-60$ & Overseas & Human Science & Professor & - \\
\hline QH-10 & M & $50-60$ & Overseas & Engineering & Professor & Centre Director \\
\hline QH-11 & M & $50-60$ & Domestic & Engineering & Associate Professor & Mid-level University \\
& & & & & & Administration \\
\hline
\end{tabular}

\section{Findings}

China's higher education development could be viewed from different perspectives. Most existent interpretations, however, have failed to capture its essence. My understanding is that its cultural meaning is the most significant. In other words, China's experience is one of cultural fusion. The efforts in higher education development is part of the nation's century-long, arduous cultural struggle to reach a balance between traditional Chinese and imported/imposed Western values. China's experiment is likely to contribute to a much altered pattern for university development that is based on the Western (European-North American) model with incorporation of the Chinese traditional understanding of higher learning. Such a claim needs to be illustrated from various aspects. What is presented as follows serves such a purpose.

\section{A Narrowing Gap}

Modern universities are uniquely European in origin and characteristics. Chinese universities are foreign transplants. Indigenous Chinese highest learning institutions only shared superficial resemblance with medieval universities in Europe (Mora 2001). For nearly two centuries, traditional Chinese emphasis on political pragmatism (Hall and Ames 2003) and the classical persistence in ontological significance of knowledge from the West have rarely been blended well. Despite of repeated attempts to indigenize the Western idea of a university (Yang 2013), the classical Western idea of a university has never taken roots in China. The strikingly different value orientations, featured respectively by 'working with (or even for) government' and 'speaking truth to power'in terms of governance mode, have led to constant conflicts in daily institutional operation and decision-making in higher education at all levels. In a context of global domoinance of the Western model (Jaschik 2011), traditional Chinese values of higher learning have been seen as a negative asset. China has not yet figured out theoretically and systematically how to combine the 'standard norms' of Western higher education with her traditional values. While Chinese universities are patterned after the Western model in terms of 
both basic infrastructure and underlying values, the Western concept of a university has only been taken for its practicality. With a long history of higher learning (Hartnett 2011), the impact of traditional values has been powerfully negative (Han 2013).

However, due to long-term diligent learning from the Western model, the extremely hard and bitter work of Chinese universities has begun to bear fruit. Fundamental values underlying the University have begun to take their roots in China most evidently at the individual level. For instance, one participant, who is an academician of the Chinese Academy of Sciences and was once the president of a regional university, said explicitly that "A truly good university must first of all have academic freedom" (QU-6). China's acceptance of the fundamental value has also been much institutionalized in universities. Even at the highest level of policy-making in higher education, the impact of such values has become more and more evident, as suggested by a senior administrator at Peking University:

It is neither impossible nor desirable for us to have academic freedom in its absolute sense. Our colleagues and (university) leaders treasure academic freedom, and indeed try to protect it whenever possible. There is much to do to strike a balance in reality. For example, when He Weifang (a law professor and an activist striving to reform China's judicial system) delivers talks here, people are nervous and would try hard to find ways to deal with possible situations. He was invited to join Zhejiang University. Our University reminded him not to resign until his transfer was confirmed. Yet, he did and even delivered his farewell speech. Then he was rejected by Zhejiang provincial government. The University had to find ways to help him and thus included him into our aid program. So he could teach at another institution for a period of time before coming back...We have very free class discussions here, and the University has strong traditions. As for autonomy in higher education reforms, we need to do it gradually. The government has become very aware of this and more and more tolerant. After all, we share similar goals. (BJ-2)

The overwhelming majority of the participants acknowledged growing autonomy granted by the government to their institutions (see, for example, BJ-2, BJ-6, QU-1, QH-9 and QH-10). A participant from Peking University elaborated such encouraging developments:

Culture really plays a critical role, especially so because of our autocratic tradition. Yet, I'm still optimistic because our society is changing in line with external environments towards one ruled by law. The society is becoming more and more mature. We shouldn't copy Oxbridge or Harvard mechanically. We'll succeed in our own context. (BJ-5)

One participant at Tsinghua made the following interesting remarks:

Academic freedom is a must. Without it, we'll never get there (world-class status). Yet, I don't think it's the best part for us to start with. China's issues require Chinese solutions. (QH-9) 
Not surprisingly, a few participants expressed their strong concerns about the corrupt role of traditional culture especially the difficulties (BJ-5) and obstacles (BJ-8) it has caused in higher education development. However, it is important to note that even those who emphasized traditional cultural values as a problem and called for "seeking truth and freedom" (BJ-8) still agreed that much progress had been made (QH-10). Such progress contributes to narrowing the conventional gap between Western and Chinese ideas of a university. They interrogate much of the mainstream literature that has predicted an impasse of China's higher education development due to a complete lack of academic freedom and institutional autonomy.

On the other hand, the government-university relationship is in a state of change in major Western societies. Universities in the Western tradition are fast becoming the technological powerhouse needed by the state, finding themselves at the mercy of the government. The state promises more and more to 'manage' creativity and innovation, while the academic pursuit of truth gets itself entangled with the commercial pursuit of prosperity. In Britain, for example, scholars are required to make themselves useful based on guides set up by governments through research councils. Former Prime Minister Tony Blair claimed that "I believe it is vital that Britain's intellectual community is full and constructively engaged in the Government's agenda and priorities. Our jobs and perspectives may be different but I believe our goals are shared" (Minogue 2001, 95).

Another strong factor in narrowing the gap is the growing problem of academic culture in Western academic circles. Academic culture has usually been cited as a major reason for China's failure to conduct cutting-edge research and deliver world-class education (see, for example, Altbach 2016, Yang 2015). It has now become an issue of concern among Western academics as well, as Adler (2014) has reported. Many things unprecedented have occurred in the last couple of decades in Western academia, in a hunger for fast, definitive answers. What has been used to accuse China is also found in major Western higher education systems including some best scholars and universities. This is not to justify China's notorious record in academic culture. It is to show the conventional gap between China and the West is narrowing in this aspect.

\section{Cultural Support}

Participants were usually asked whether they were optimistic or pessimistic about China's quest for world-class university status. They tended to express their optimism openly and firmly (BJ-1, BJ-2, BJ-5, BJ-6, BJ-7; QH-1, QH-2, QH-4, QH-5, QH-7, QH-8), even some complained much about their social, political and institutional environments (BJ-8, QH-10). Interestingly, their complaints and confidence appeared to be somewhat contradictory, and this echoes the situations in Hong Kong, Singapore and Taiwan: strong optimism with clear inability to substantialise their differences from the experiences of Western universities.

In the case of the Chinese mainland, at least two factors can explain such a seemingly paradox. First, ever since the late Qing dynasty especially after the May Fourth Movement in 1919, traditional Chinese cultural values have been strongly criticised as a major reason for China's "ignorance and backwardness" in a context Western prestige (Schwarcz 1986). This has greatly marginalised the traditions that could have made possible contributions in China's cultural encounters with the West. Accordingly, major Western universities have been deified to the extent that it is often beyond the imagination of many Chinese within universities to think of problems of such institutions.

Most recently, however, as China continues to develop well and engage with the West, people become more confident about themselves and the society. At the same time, they become more 
knowledgeable about the outside world. Their attitude to and knowledge of traditional Chinese culture have also changed, with a better understanding that Chinese cultural traditions could have a positive role to play as well. Confidence in traditional Chinese culture is resuming, as illustrated by the following remarks:

It's a matter of time (to achieve world-class status), but hard to say when. We need to wait and we are all hopeful. Once we reach certain level, we will have our own features accumulated for a long time of development. (BJ-2)

A "glass ceiling" might exist. It might be 10 meters high. We are not there yet, perhaps only 2-3 meters high. Once we are there, we might find some cracks in it, or we can see whether it's thin or think. We might find ways to get through or avoid it. Our world-class universities will take some time to achieve, but we will get there. (BJ-6)

We need to do well by some hard indicators in order to be acknowledged internationally as world-class... Our future looks bright. We have built up our hardware. We will succeed. But it's not the time yet to claim a comprehensive win. (BJ-7)

Still, very few could link it well with higher education development in a more defined theoretical manner. This is mainly because modern Chinese universities have little linkage to their traditional roots. A participant from Tsinghua University made the following analysis:

We need to have our own understanding of civilization to support our work and life. Don't always focus on catching up. Catch-up mentality is utilitarian, not scientific. Our research planning shouldn't be dominated by such a mind-set. With our development today, we need to rethink the future of our civilization. Otherwise, we'll be bogged down in a quagmire of low-level competition. (QH-9)

China's rich intellectual traditions have their strengths with a great potential to contribute to the Chinese idea of a university. It offers favourable conditions for the combination of both Chinese and Western traditions. Its provisional and open perspective, which is hard for those personally committed to more absolute faiths to comprehend, allows the Chinese to be able to appreciate opposing poles as a driving force and see opportunities in contradiction. The pragmatic approach to life further enables them to use whatever helpful means that are available to settle or solve problems or issues (Wong 2001). As for the idea of a university, they do not have to choose one between the seemingly contradictory Chinese and Western university models. Instead, they could have ambivalence and flexibility to achieve an integration of both.

Without specializing in higher education, it was understandable that most participants did not provide an explicit intellectual foundation for their confidence. However, their confidence is well based. According to Wang Yingjie (2003), the dominant model of the American research university might be viewed as a house with rooms that are not connected to each other, caused by its close historical links to the industrialization process and led to the segregation of specialist disciplines, of research and teaching, of knowledge transmission and the cultivation of character, and of university and society. Chinese culture could contribute to increasing integration of 
humanity with the universe, balancing individuals, society, and the natural environment; of learning with life, balancing individual goals with national and global ones; of morality with knowledge, ensuring that moral formation is viewed as a core aspect of university education; of knowing and doing, which would foster capability for action as well as theoretical understanding; and of teaching and learning through a dialogic approach.

\section{A Mix of the Chinese and the Western}

As a latecomer, China's modernization involves a response to Western challenges. The desire to catch up with the West has always been fervent. Most recently, the strive for internationally competitive universities provides an impetus for China's best institutions to follow the lead of European and North American universities and embrace "international” norms. Especially with recent impressive development, top Chinese universities now compare themselves increasingly with their prominent Western peers such as Oxford and Yale. Nearly all the participants mentioned major global universities in one way or another and almost no exception those were Western institutions. It was common to hear they mention major Western counterparts when they talked about their international networks, strategic collaboration and the positions of their programs in global ranking systems. One participant who was then both a mid-level administrator and a deputy dean at Peking University said, "We are still in a process of catching up. At this stage, our strategic priority is to become the same as Oxford, Cambridge, Princeton and Yale" (BJ-2).

Some, usually from social sciences and the humanities, had broader perspectives including the historical and the foreign. At Peking University, for instance, a mid-level administrator compared the history of Chinese modern universities with Oxford and Cambridge and argued that Chinese universities needed more time to establish their own identities, values and cultures (BJ-2). One dean illustrated how he introduced "Western management" into his own faculty (BJ3). A mid-level administrator who is a historian by training compared China's encounters with Western culture with Japan's experience (BJ-7). A law professor pointed out some core values that originated from the West and stressed their great significance for China (BJ-8), and his comments were strongly supported by a prominent engineer at Tsinghua University (QH-6).

One participant who was then a mid-level administrator at Peking University and scientist by training said "Third-class dean stresses efficiency. Second-class dean pays attention to management. First-class dean watches for culture” (BJ-5). Here culture, management and efficiency are all combination of Chinese and Western values. They echo the comments by another participant at Tsinghua University who has a background in business and management: "If you observe successful businessmen in China today. They all have Chinese values for conducting oneself and Western values for conducting business” (QH-5).

The fact that nearly all participants included Western knowledge in their talks has to be understood in a context of contemporary Chinese society and culture that have been profoundly influenced by Western values, as a consequence of the Westernization of the world (Latouche 1996). According to UNESCO (1998), the world's chief educational practices are Western, as initially conceptualized in ancient Greece, adapted by ancient Romans, limited by the European Middle Ages, expanded by the Renaissance, and rationalized by the industrial and scientific revolutions. While there are variations on the theme and differences in interpretation, it is difficult today to find a widespread educational practice that is radically different from the dominant secular educational paradigm of the West (Elliott and Grigorenko 2007). Western knowledge has become part of China's contemporary knowledge system. It is already impossible 
for the Chinese to talk about formal education without mentioning the West. This is most evident in the speeches delivered by university presidents as well as in institutional development plans. Such combination is well illustrated by the following observation:

As for (disciplinary) knowledge, I think Chinese universities should emulate the West. We need at least to have some breakthroughs in certain fields. Such breakthroughs require genuine learning from the West (spirit of seeking truth) with great respect... Our problem is that our tradition has not been activated while our understanding of Western learning is shallow. We have never truly understood Western knowledge. This is why there still lacks an integration of both traditions, although some progress has been made. (QH-9)

In an era of globalisation, being able to learn from other culture has become critically important for sustainable development of any society (Cheng 2007). More specifically, for research on China's higher education, the combination of the Chinese and the Western has some significant implications: firstly, it questions seriously the conventional dichotomy of the two in the literature on Chinese higher education and treats the Chinese as the Other; secondly, it reminds us of the great extent to which China has absorbed Western knowledge in many aspects at individual, institutional and systemic levels; and thirdly, it demonstrates that it is no longer valid to draw a clear dividing line between Chinese and Western ideas of a university.

\section{Two Other Major Factors}

Since the ti-yong (substance-application) bifurcation of Chinese and Western learning in the $19^{\text {th }}$ century, China has been struggling with its countering with the West (Kwong 1993). The method of self-strengthening envisioned by Confucian reformers was based on a belief that China should maintain its own style of classical learning based on ethics to keep the "essence" of society, while at the same time using Western learning for "practical application" in developing its infrastructure and economy. The essence and application later swapped as China adopted more Western values and systems (Li 1987). Different much from its culturally similar neighbour Japan which decided to have juxtaposition of Japanese and Western traditions without much assimilation, China has always aimed at integrating tradition with modernity. Such an approach has proved the most difficult. It requires a number of other supporting factors. China now poses to have a better chance with some of her advantageous factors of which some were emphasized by the participants.

The first is China's recent economic growth that enables the nation to invest heavily on science, technology and universities, as shown by the following remarks:

You have seen our new buildings including the library, many of them. They were all built recently. This is a necessary part of our world-class movement. (BJ-3)

Our innovation has been accelerating because we've got the money and the people (needed), plus the culture we have, we'll certainly develop further. (BJ-2)

For many at Tsinghua University, the impact is even more evident as their work is usually labbased (QH 2, QU-5 and QH-8). One of them said: 
In terms of hardware including research facilities, quality and output, the gap (between Tsinghua and world's best universities) is becoming very thin. In terms of real matters, such as Chinese characteristics and Tsinghua style, we've got lots to think and do. (QH-3)

Another factor is China's large pool of talents. Sitting at the very top of China's higher education system, the two universities have the privilege to recruit the nation's best students. Thus, it was common among participants to mention repeatedly that students were their "biggest advantage" (BJ-2, QH-1, QH-5 and QH-8). In addition to the intelligence of the students, some participants at Tsinghua University stressed their steadfast attitude towards work (QU-10).

Of course, China's talent advantage goes beyond students, as one participant from Peking University with a background in the humanities shared with me his experience as follows:

I remember a few years ago I delivered a talk on China's social change at the University of Tokyo. During Q\&A, one renowned anthropology professor made comments on a question by someone else about the small percentage of China's elites. He explained even a low percentage of China's population actually meant a large number. He obviously knew China well and pointed out many major universities in various regions such as Lanzhou, Jilin and Sichuan. I was impressed by their awareness of China’s large pool of talents. (BJ-7)

Echoing this, one participant from Tsinghua University said, “It won't take too long for China to have Nobel Prize winners simply because of the population size” (QH-10).

\section{Conclusion}

China's higher education has made impressive progress over the past decades while at the same time faces serious problems. Both its achievements and difficulties are sufficiently extraordinary to challenge the existing pessimistic and optimistic views about China's future development in higher education. No theory could properly explain what has already been happening in China. Few - both within China and internationally - have been able to come to good terms with China's experience. This was confirmed repeatedly by my interviews with the Chinese higher education and academic elites. Although most of them expressed their confidence explicitly, none of them could substantialize theoretically how and why their experiences differed from those of Western universities. There is a need for new perspectives to observe Chinese experiment, focusing on the cultural mission of China's most elite universities. While it remains to be seen how Chinese higher education would fare in the years to come, emerging signs show how China's longstanding efforts to learn from the West has begun to pay off. The best universities have demonstrated a possibility of striking a balance between Chinese and Western ideas of a university that have been conventionally perceived as mutually exclusive.

Recently, some have employed the notion of soft power to analyse China's international engagement in higher education. However, such discussions cannot fully capture the essence of China's higher education development and its implications. Set in an inexplicit yet powerful context of conflicting national self-interests, the notion is a Western construction, with deep roots in modern history featured by conflicts. As demonstrated by the word "power," its central focus is on conflicts. It is little surprising that the concept is a close relative of clash of civilizations (Iriye 1997). The notion likely leads to a view of China's rising soft power as a 
zero-sum game (Ramani 2005). Along this line, it is natural to judge whether Chinese universities are followers or leaders (Wende and Zhu 2016). As a civilisation state, China's global engagement in higher education functions more than a soft power. The cultural mission of Chinese modern higher education aims to combine Chinese and Western elements to bring together the aspects of both philosophical heritages. Such a notion provides us with a much more meaningful perspective to assess China's higher education development and its global implications.

Acknowledgments This work is part of the General Research Fund project entitled "Integrating Chinese and Western Higher Education Traditions: A Comparative Policy Analysis of the Quest for World-class Universities in Mainland China, Hong Kong, Taiwan and Singapore” (751313H) supported by the Research Grant Council, Hong Kong Special Administrative Region.

\section{References}

Academic Ranking of World Universities 2017. World Top 500 Universities. Accessed August 23, 2017. http://www.shanghairanking.com/ARWU2017.html

Adler, J. 2014. The Reformation: Can Social Scientists Save Themselves? Pacific Standard, April 28. Accessed April 9, 2017. https://psmag.com/the-reformation-can-social-scientists-savethemselves-8c2f834715a7

Altbach, P. G. 2016. "Chinese Higher Education: 'Glass Ceiling' and 'Feet of Clay.' International Higher Education 86 (Summer): 11-13.

Ball, S. J. 1994. Education Reform: A Critical and Post-Structural Approach. Buckingham and Philadelphia: Open University Press.

Cheng, C. Y. 2007. "Philosophical Globalization as Reciprocal Valuation and Mutual Integration: Comments on the Papers of Tang Yijie and Roger Ames.” In Dialogue of Philosophies, Religions and Civilizations in the Era of Globalization, 65-76. Edited by D. H. Zhao. Washington, D.C.: The Council for Research in Values and Philosophy.

Elliott, J. and E. Grigorenko. 2007. Western Psychological and Educational Theory in Diverse Contexts. London: Routledge.

Guo, Y. 2016. Statistics of Chinese Scientific Papers. Accessed August 23, 2017. http://news.sciencenet.cn/htmlnews/2016/10/358134.shtm

Hall, D. L. and R. T. Ames. 2003. A Pragmatist Understanding of Confucian Democracy. In Confucianism for the Modern World, Edited by D. A. Bell and C. B. Hahm, 124-160. Cambridge, UK: Cambridge University Press.

Han, S. H. 2013. "Confucian States and Learning Life: Making Scholar-Officials and Social Learning a Political Contestation.” Comparative Education, 49 (1): 57-71.

Hargreaves, D. 1993. Whatever Happened to Symbolic Interactionism? In Controversies in Classroom Research. Edited by M. Hammersley, 135-152. Buckingham: Open University Press.

Hartnett, R. 2011. The Jixia Academy and the birth of higher learning in China. Leweiston, N.Y.: Edwin Mellen Press.

Hawkins, J. N. 2013. East-West? Tradition and the Development of Hybrid Higher Education in Asia. In The Dynamics of Higher Education Development in East Asia. Edited by D. Neubauer, J. C. Shin and J. N. Hawkins, 51-67. New York: Palgrave Macmillan.

Hayhoe, R. 1996. China's universities 1895-1995: A century of cultural conflict. New York: Garland. 
Henry, M., B. Lingard, F. Rizvi, and S. Taylor. 1997. Educational Policy and the Politics of Change. London: Routledge.

Iriye, A. 1997. Cultural Internationalism and World Order. Baltimore: John Hopkins University Press.

Jacob, W. J. 2006. "Social Justice in Chinese Higher Education: Regional Issues of Equity and Access.” International Review of Education, 52 (1): 149-69.

Jaschik, S. 2011. "How Asian are Asian Universities?” Inside Higher Ed March 14.

Kigotho, W. 2014. “China's Rapid Rise in Global Science and Engineering.” World University News 309, February 28.

Kwong, S. K. L. 1993. “The Ti-Yung Dichotomy and the Search for Talent in Late Ch’ing China.” Modern Asian Studies, 27 (2): 253-79.

Latouche, S. 1996. The Westernization of the World: The Singnificance, Scope, and Limits of the Drive towards Global Unifiormity. Cambridge: Polity Press.

Li, Y. A., J. Whalley, S. M. Zhang, and X. L. Zhao. 2011. "The Higher Educational Transformation of China and Its Global Implications.” The World Economy, 34 (4): 516-45.

Li, Z. H. 1987. A Study of the Intellectual History of Modern China. Beijing: Oriental Publishing House. (In Chinese)

Marginson, S. 2006. "Dynamics of National and Global Competition in Higher Education." Higher Education, 52 (1): 1-39.

Marginson, S. 2014. "New Empires of Knowledge in East Asia.” Tsinghua Journal of Education 35 (6): 1-12. (In Chinese)

Marshall, C., and G. Rossman. 2006. Designing Qualitative Research. Thousand Oaks, CA: Sage.

Miles, M. and A. Huberman. 1994. Qualitative Data Analysis (2nd ed.). London: Sage.

Min, W. F. 1991. "Higher Education Finance in China: Current Constraints and Strategies for the 1990s.” Higher Education, 21 (2): 151-61.

Ministry of Education. 2017. National Education Statistics Bulletin in 2015. Accessed August 23, 2017. http://www.moe.gov.cn/jyb_sjzl/sjzl_fztjgb/201707/t20170710_309042.html

Minogue, K. 2001. The Collapse of the Academic in Britain. In Buckingham at 25: Freeing the University from State Control. Edited by J. Tooley, 86-100. London: The Institute of Economic Affairs.

Mohrman, K. 2005. Sino-American Educational Exchange and the Drive to Create World-Class Universities. In Bridging Minds Across the Pacific. Edited by C. Li, 219-35. Lanham: Lexington Books.

Mora, J. G. 2001. “Governance and Management in the New University.” Tertiary Education and Management, 7: 95-110.

Morgan, J. 2011. "Sun Sets on Western Dominance as East Asian Confucian Model Takes Lead.” Times Higher Education, February 24.

Morrison, J. 2014. “China Becomes World's Third-Largest Producer of Research Articles.” Nature, February 6.

O’Leary, Z. 2004. The Essential Guide to Doing Research. London: Sage.

Punch, K. 2009. Introduction to Research Methods in Education. London: Sage.

Ramani, S. 2005. “Interview: Joseph Nye.” The Diplomat, June 10.

Rhoads, R. A., X. Y. Wang, X. G. Shi, and Y. C. Chang. 2014. China's Rising Research Universities. Baltimore, Md.: Johns Hopkins University.

Schwarcz, V. 1986. The Chinese Enlightenment: Intellectuals and the Legacy of the May Fourth Movement of 1919. Berkeley: University of California Press. 
Travers, M. 2001. Qualitative Research Through Case Study. London: Sage.

UNESCO. 1998. World Education Report 1998. Paris: UNESCO Publishing.

Van Noorden, R. 2016. “China by Numbers.” Nature, 534 (7608), 452-453.

Wang, Y. J. 2003. "A New University Model for the New Century: From Perspectives of Chinese Philosophy." Paper prepared for the Learning Conference 2003 organized by the Institute of Education, University of London, July 15-18.

Wang, X. 2010. Higher Education as a Field of Study in China. Lanham, Md.: Lexington Books.

Wende, M. C. van der., and J. L. Zhu. 2016. China: A Follower or Leader in Global Higher Education. Research and Occasional Paper Series: 1.16, Centre for Studies in Higher Education, University of California, Berkeley.

Wong, K. C. 2001. “Chinese Culture and Leadership.” International Journal of Leadership in Education, 4 (4): 309-19.

Yang, R. 2011. "Self and the Other in the Confucian Cultural Context: Implications of China's Higher Education Development for Comparative Studies.” International Review of Education, 57 (3-4): 337-55.

Yang, R. 2013. "Indigenizing the Western concept of the university: Chinese experience.” Asia Pacific Education Review, 14 (1): 85-92.

Yang, R. 2015. "Reassessing China's higher education development: A focus on academic culture.” Asia Pacific Education Review, 16 (4): 527-535.

Yang, R. 2016. Cultural Challenges Facing East Asian Higher Education: A Preliminary Assessment. In The Palgrave Handbook of Asia Pacific Higher Education. Edited by Christopher S. Collins, Molly N.N. Lee, John N. Hawkins and Deane Neubauer, 227-45. New York: Palgrave Macmillan. 